Buddhist thought on bioethics. One of the great values of cross-cultural studies is that they provide fresh insights and solutions to problems in one's own culture. Westerners, in their attempt to come to some acceptable way of dealing with the legal and ethical dilemmas of abortion, could benefit quite a lot by considering the Buddhist approaches to this problem that $\mathrm{Dr}$ Keown details.

Buddhism and Bioethics begins with a short introduction that has a good thumbnail presentation of the basics of Buddhism and which raises six fundamental methodological questions in Buddhist ethics and cross-cultural ethics which guide the book. In paraphrase, the questions are: (1) Does cross-cultural ethics demand its own special methodology?; (2) Is there such a thing as the Buddhist view on ethical questions or are there only views of particular Buddhist individuals and schools from particular places and times in the vast temporal and cultural sweep of Buddhist history?; (3) What is the role of scripture in establishing moral norms in Buddhism?; (4) Are Buddhists moral absolutists or situation ethicists?; (5) What is the moral status of non-human life in Buddhist ethics? and (6) What is the role of compassion in Buddhist ethics?

His answers to these questions are very clear and well argued, but, in some cases, I believe his positions are somewhat incorrect. In particular, his insistence that there is "a Buddhist view" on various specific bioethical issues is perhaps too easily arrived at. He puts tremendous weight on data from the ancient scriptures of Theravada Buddhism, the Buddhism practised in South East Asia, including Thailand and Sri Lanka. He regards these texts, which he knows very well in their original language, together with one particular classical scholar, as normative. He admits to being a sort of "Buddhist fundamentalist" and very conservative on these issues.

I believe that later Mahayana texts and tradition are no less normative and that more attention should have been given to anthropological, fieldbased studies. My research has led me to conclude that it is much more accurate to speak of "Buddhist approaches" rather than to postulate one normative "Buddhist view" on these complex issues. My view of the Buddhist tradition is that it is much more relativistic and situational than Keown's view, which sees Buddhist ethics as normative and absolute. However, this is not a condemnation of Keown's study which has the virtues of clarity, careful argument, and deep grounding in the primary texts and scholarly literature.

The bulk of the book is in the form of three long chapters. The first lays out a theory of Buddhist bioethics; the second focuses on the issues that cluster around the beginning of life (including abortion, embryo experimentation, artificial insemination, and the like); the third treats the end of life (including coming to a Buddhist definition of death, euthanasia, and suicide). Obviously then, many important issues in biomedical ethics, such as the right to health care, allocation of scarce resources, genetic counselling, environmental ethics, and so forth are not covered in the book. This is not a particular weakness, as it would have been far too ambitious, and the book would have been far too long if the author had attempted everything.

In general, Keown's treatment of the topics he does focus on is very comprehensive. He develops Buddhist positions on a wide range of specific ethical problems, such as artificial insemination with sperm donation from husband and from non-husband; and the ethical status of twinning and recombining embryos; and he provides finely distinguished categories of euthanasia. Much of this is truly original work, the very first attempts to deal with some of these issues from a Buddhist perspective. On the whole, his strength is his clear theoretical approach and his weakness is in dealing with the reality of Buddhist practices in the modern world. For example, his discussion of abortion practices in Sri Lanka and Thailand is very careful, but does not take into account the latest field studies.

All in all this is a very good book, highly recommended to anyone interested in the field. No academic library should be without it.

ROBERT E FLORIDA Dean of Arts, Brandon University, Brandon, Manitoba, R7A 6 A9 Canada

\section{Children as Research Subjects: Science, Ethics and Law}

Edited by $\mathrm{M}$ A Grodin and $\mathrm{L} \mathrm{H}$

Glantz, New York and Oxford,
Oxford University Press, 1994, $258+$ xiii pages, $£ 30.00$.

The use of children as subjects of medical research was first controlled legislatively nearly 100 years ago, with a 1900 law preventing most such research in Prussia. In 1931 a German law made non-therapeutic research on minors (under 18) illegal. The UK Medical Research Council in 1962 also concluded that non-therapeutic research on children was unlawful. Yet in the last 30 years the protection of children from research risks has been so eroded that even the injunction that research be performed first on adults capable of consent is now ignored in the field of gene therapy.

This multi-author volume from the United States does little to stem such erosion, and in places encourages it. Dan Brock, a professor of biomedical ethics, for instance, considers the way in which children benefit from the results of earlier research, and "... establishes not just that it is ethically permissible for children to participate in research not expected to be of benefit to them but that it is ethically obligatory for them to do so". In a valuable chapter on vulnerable children, Robert Cooke, a paediatrician, does argue against carrying out any non-therapeutic research on such children if the risk is greater than minimal, but does not argue for similar protection to be available to children not defined as vulnerable.

This is the first attempt by American authors since the 1977 report and recommendations of the US National Commission for the Protection of Human Subjects of Biomedical and Behavioral Research, to provide a comprehensive review of research with children. It is therefore to be welcomed since it should encourage a new generation of American paediatric researchers to think carefully about their duties to child research subjects.

That may, however, be the limit of its value, since it suffers from a disease now epidemic in the United States: academic xenophobia. Of over 500 references, fewer than 20 are to work published outside the United States; one-third of those citations are incorrect, as if the primary source had not been consulted. By largely ignoring relevant non-American work, the authors fail to take forward the debate about the protection of children. Thus the difficulties of obtaining consent to research into emergency care, such as resuscitation or early neonatal care, 
are not discussed. Neither are the very broad, qualitative statements about the definition of minimal risk - a crucial issue - any more precise than 20 years ago.

Saddest of all is the ignoring of the empirical studies of Priscilla Alderson in the UK, which should be revolutionising the involvement of children in medical decision-making. A long chapter on the latter is based largely on psychological constructs, from which comes a rather fuzzy message that only older adolescents are capable of consenting to research involvement.

Yet Dr Alderson has shown that children as young as seven have the ability to give informed consent, not just the assent that is all that the American authors think them capable of. Recognising that ability allows one to work in partnership with children and parents. The problem with Children as research subjects is that it still regards research with children as a paternalistic activity and does not address the possibility of it being a partnership. Yet were that paternalism full-blooded, it would wish to reverse the erosion of children's protection in research. Because the authors do not consider the debates outside the United States, they are caught, untenably, between paternalistic and respectful approaches to protecting children. Recognition of the great amount that children can and do understand about medical proposals demands respect for them, which should translate into the practice of research as a common enterprise, a partnership - an idea first proposed in fact by a great American, Margaret Mead, a quarter of a century ago.

DR RICHARD NICHOLSON Editor, Bulletin of Medical Ethics

\section{The Healing Arts: an Oxford Illustrated Anthology}

Edited by R S Downie, Oxford, Oxford University Press, 334 pages, $£ 18.99$.

This book is a gem which will have wide appeal. The chosen title emphasises that the arts and medicine have the common purpose of healing dis-ease. It breaks new ground in using art, prose and poetry to explore interactions between medicine and the arts. The purpose is to provide multiple perspectives and deep insights into the reactions of patients, their friends, doctors, and others to disabilities, illness and other life events.

The extracts and illustrations are all well chosen and illuminating; taken together they build up a varied and valuable whole that fulfils the ambitious aim of the book, as well as being stimulating and entertaining. The editor's commentary steers us through the chosen topics with a skilful but light touch, leaving the poets, authors and artists to build up the rich canvas. Readers are likely to be stimulated to seek out and read in full much of the source material.

The contributions blend into a structured miscellany, providing new viewpoints on the varied ways that people think, feel, manage, or fail to cope as they experience the events that characterise the human condition. The authors and artists vary from household names to the relatively unknown, and include such diverse sources as Pepys on the great plague, travels with Lord Byron, Zen and the Art of Motorcycle Maintenance, Catch 22, a case study of Beethoven, poems by Philip Larkin, William Blake and John Donne, and portraits by Rembrandt and Sir Roy Calne. The book is divided into sections covering areas such as birth, growing up, love, maturity and ageing, disease and mental illness, doctors and psychiatrists, nurses and patients, healing, caring, death and dying. Many of the extracts chosen will deepen mutual understanding between professionals and patients.

This book can with profit be dipped into anytime, but I hope it will also be read, thought about and valued. There is much in it that we need to learn and understand.

RICHARD WEST Medical Postgraduate Department, University of Bristol

\section{Ethics and Perinatology}

\section{Edited by A Goldsworth, W} Silverman, D K Stevenson, E W D Young and R Rivers, Oxford, Oxford University Press, 1995, 484 pages, $£ 50.00$.

This book of US/UK origin is a major text which covers most of the main moral, legal and economic issues generated by the practice of perinatology in the Western world. The contents are interestingly arranged, with each of the 14 topics being introduced by an experienced clinician and followed by an extensive commentary by an appropriate expert from the fields of academic law, bioethics, health economics or philosophy. This method has succeeded because each of the contributions from the team of 32 well-chosen authors is of high quality and is well-fitted to the intended design.

The avowed purpose is to "address ethical issues confronted by those caring for fetuses, newborns and their families" but the emphasis is almost entirely on those dilemmas closely touching the providers and recipients of treatment in neonatal intensive care units (NICUs).

This field of technologically driven medical and nursing practice is now sufficiently established and demarcated to justify an ethical compendium devoted to the specialty. But the thoughtful question asked on page 327 by Margaret Brazier: "Are there in reality ethical problems of perinatology, or are such problems particular applications of more general issues concerning prolonging life and the euthanasia controversy?" is not fully answered.

The ethical frame is the now conventional US/UK paradigm of medico-moral reasoning: Hippocratic code, the four pillars of philosophic principle enunciated by Beauchamp and Childress, commitment to a pluralistic interpretation of the golden rule and a leaning towards a utilitarian ethic in which fairness replaces felicity.

The sections on: prolonging life and causing death, the participation of infants in research, informed consent, organ transplant and the economics of cost-hungry intensive care show that there are difficulties in generalising the "principled" approach to some particular perinatal situations.

Informative and useful chapters about the body of legal and regulatory measures which impact on perinatal practice reveal interesting differences between US and UK attitudes and processes. The extent to which these account for variation in clinical behaviours and ethical decisionmaking is worthy of further discussion.

Some consideration of the non-rational elements which complement the philosophical analytic approach surfaces in a plea for a more virtue-based ethics from the writers on paediatric nursing, and in the two illuminating chapters on religious influences. One is 